\title{
Multiband Cross-Shaped Inverse Triangular Notch Antenna for Radio Shadow Zone Communication
}

\author{
Kyeong-Sik Min*
}

\begin{abstract}
This paper proposes a multiband cross-shaped inverse triangular notch antenna on a circular ground plane for a radio shadow zone mobile communication design for a broadband repeater antenna in the firefighting band for in-building mobile communication. To arrive at the broad and multi-bandwidth reflection coefficients, methods are considered for optimizing the cross-shaped notch antenna with an inverse triangular structure and the circular ground plane. The measured reflection coefficients are observed $-10 \mathrm{~dB}$ lower in the firefighting band (440-450 MHz) and the mobile repeater band (890-2,450 MHz), and they agree well with those obtained through simulation. The desired omni-directional patterns are obtained in the firefighting band, even though the radiation patterns in the $\mathrm{Wi}-\mathrm{Fi}$ band have directivity from $10^{\circ}$ to $15^{\circ}$ and from $-10^{\circ}$ to $-50^{\circ}$. The measured radiation patterns and gains also agree well with the predictions.
\end{abstract}

Key Words: Broad and Multi-Bandwidth, Cross-Shaped Notch, Discone Antenna, Firefighting Radio Band, In-Building Mobile Communication, Mobile Repeater, Radio Shadow Zone.

\section{INTRODUCTION}

Wireless communication in the radio shadow zone, such as a building cellar or underground, has not been aggressively improved, even though mobile communication has been rapidly developed. To satisfy the bandwidth required for wireless communication, various broadband printed dipole antennas have been proposed [1, 2] mainly as small antenna applications. In [1], a coupled-fed printed dipole antenna for direction finding was operated at 1.575-2.4 GHz. In [2], a printed dipole antenna with a split-ring resonator showed good resonance results of 1.4-2.5 GHz. Although these types of antennas show good performance, the fundamental problems of a low-gain and high-frequency operation due to antenna size are not yet solved. A microstrip patch array antenna for indoor repeater application was proposed in [3]. As an important application for mobile communication in places such as the inside of a building or an offshore plant structure, radio shadow zones that hinder communication can develop. To solve this problem, various antenna designs have been considered for in-building mobile communication [4-6]. Specifically, a radio firefighting alarm system should be established legally in buildings in Korea. As the firefighting radio band of $440-450 \mathrm{MHz}$ is of a lower frequency than the mobile indoor repeater band, creating a multiband single-antenna design poses a challenge. The antennas mentioned in $[1,2,7]$ have not been operated in a low-frequency band, such as the firefighting radio band and the LTE band 5. Even these antennas are broad bandwidth and achieve good performance at the mobile communication band. Owing to its broad bandwidth and omni-directional radiation pattern, a discone

Manuscript received September 21, 2020 ; Revised October 21, 2020 ; Accepted October 26, 2020. (ID No. 20200921-150J)

Department of Radio Communication Engineering, Korea Maritime and Ocean University, Busan, Korea.

"Corresponding Author: Kyeong-Sik Min (e-mail: ksmin@kmou.ac.kr)

This is an Open-Access article distributed under the terms of the Creative Commons Attribution Non-Commercial License (http://creativecommons.org/licenses/by-nc/4.0) which permits unrestricted non-commercial use, distribution, and reproduction in any medium, provided the original work is properly cited.

(c) Copyright The Korean Institute of Electromagnetic Engineering and Science. All Rights Reserved. 
antenna operating at very high frequency (VHF) band has been considered for ultra-wideband applications [8]. A discone antenna has also been proposed to reduce antenna size [9]. Although several low-profile antennas for the VHF band were proposed in $[8,9]$, they were not enough for high-frequency bands, such as Wi-Fi, LTE, and $5 \mathrm{G}$ mobile communication, mainly because of radio shadow zone applications, such as inbuilding cellars or underground. Therefore, the design of a novel multiband antenna for radio shadow zones is greatly required [5-7]. In keeping with the national legal requirement, a broadband antenna for radio shadow zones, including in-building mobile communication, such as the firefighting radio band, LTE band 5, and mobile repeater band, is continuously being designed and proposed [4-6]. However, designing a multiband single-antenna with a firefighting radio band of $440-450 \mathrm{MHz}$ is not easy. Overcoming the difficulties inherent in a multiband antenna design poses a challenge. A multiband cross-shaped inverse triangular notch antenna on the circular ground plane for radio shadow zone communication is proposed in this paper. To realize multiband characteristics, the notch antennas for ultra-wideband with a band stop have been studied [10,11]. As similar approach for multiband performance, a notch structure was considered. To achieve broad bandwidth and omnidirectional radiation pattern for a firefighting radio application, an advanced discone antenna structure was applied in this study. To utilize the discone antenna characteristics, a cross-shaped inverse triangular structure was adopted in this study. Therefore, the important characteristics of the proposed antenna such as broadband and omni-directional radiation pattern by a crossshaped inverse triangular structure, and a multi-resonance by a notch structure were implemented. These characteristics were simulated by the HFSS (ANSYS Inc., Canonsburg, PA, UAS). Especially, an omni-directional radiation pattern is commonly implemented by a cross-shaped notch antenna similar with a discone antenna principle.

A conventional circular discone antenna must have an unwieldy size to accommodate the firefighting radio band [5]. To solve this problem, a circular ground plane diameter of 200 $\mathrm{mm} \phi$ is considered, even though its wavelength is too short compared with the firefighting band. The resulting design has multiband capabilities, and its application service band covers the firefighting radio band (440-450 MHz), LTE band 5 (824$894 \mathrm{MHz})$, DSC band (1,710-1,880 MHz), PCS band (1,8501,990 MHz), WCDMA1 band (1,920-2,170 MHz), and WiFi $802.11 \mathrm{~b} / \mathrm{g}$ band $(2,400-2,470 \mathrm{MHz})$. Therefore, a broad bandwidth capability was achieved by adjusting the length and width of the circular ground plane and the cross-shaped notch element. The proposed antenna exhibited reasonable reflection coefficients of $-10 \mathrm{~dB}$ lower, covering the firefighting radio band and the mobile repeater band. The simulated radiation patterns and gains also agreed well with the measured patterns.

\section{ANTENNA DESIGN}

Fig. 1 shows the structure of the cross-shaped inverse triangular notch antenna on the circular ground plane. The crossshaped notch parameters having a reverse triangular structure are fed by a probe through the center of the circular plate, as shown in Fig. 1(c). The dielectric substrate considered in this antenna design is the FR-4 epoxy substrate of $1 \mathrm{~mm}$ thickness, with a relative permittivity of $4.4+j 0.04$. The circular plate shown in Fig. 1(a) is the ground plane; its diameter is fixed at $200 \mathrm{~mm} \phi$ in the simulation.

To better understand the cross-shaped inverse triangular notch behavior of the antenna, the impedance characteristics by the reflection coefficients with respect to the various parameters as shown in Fig. 1 are presented and discussed. The optimum parameters of a proposed antenna are obtained by iteration. For

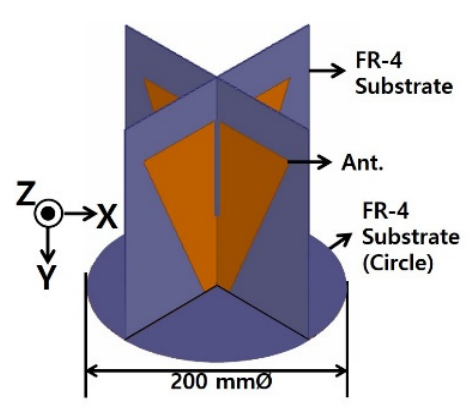

(a)

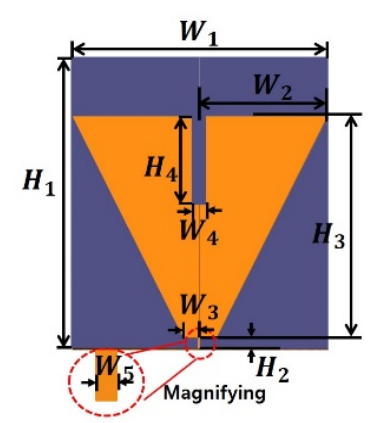

(b)

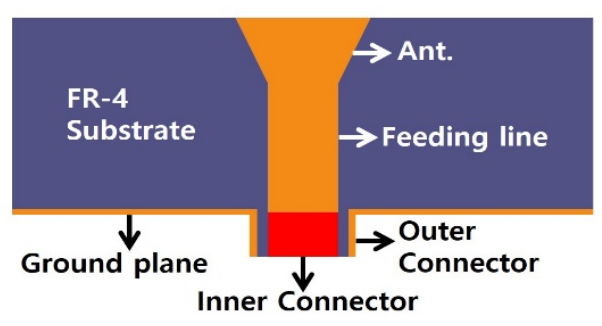

(c)

Fig. 1. Structural design of the cross-shaped notch antenna: (a) 3D structure, (b) side view, and (c) magnified feeding structure. 
example, satisfying for broad bandwidth of a cross-shaped inverse triangular structure, the reflection coefficients as functions of the various parameters are simulated and derived as shown in

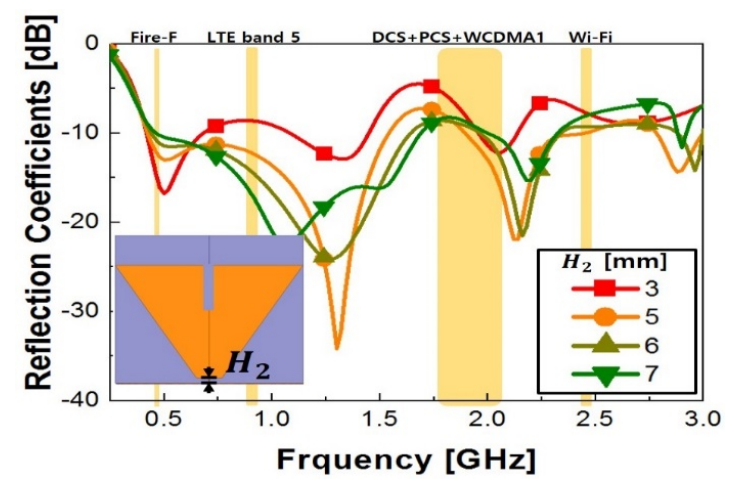

(a)

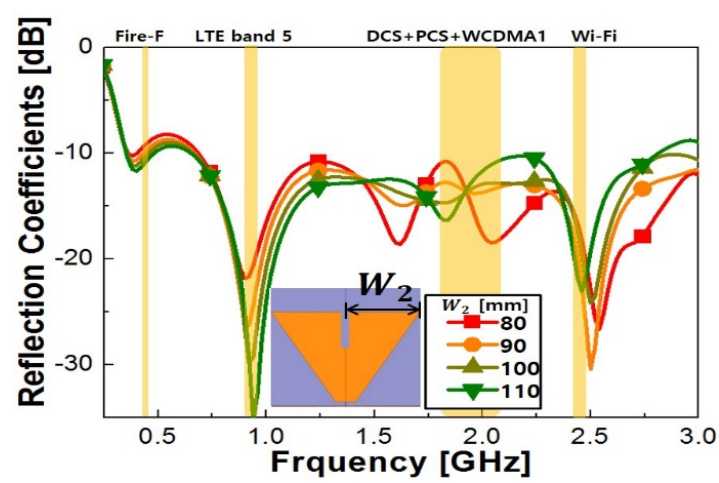

(c)

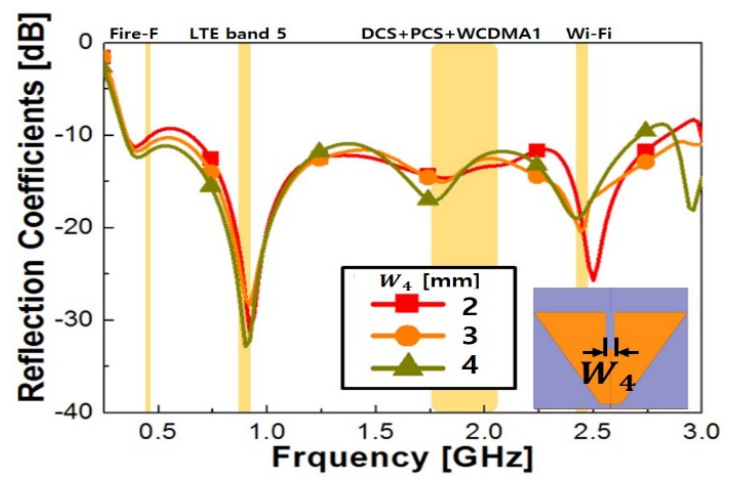

(e)

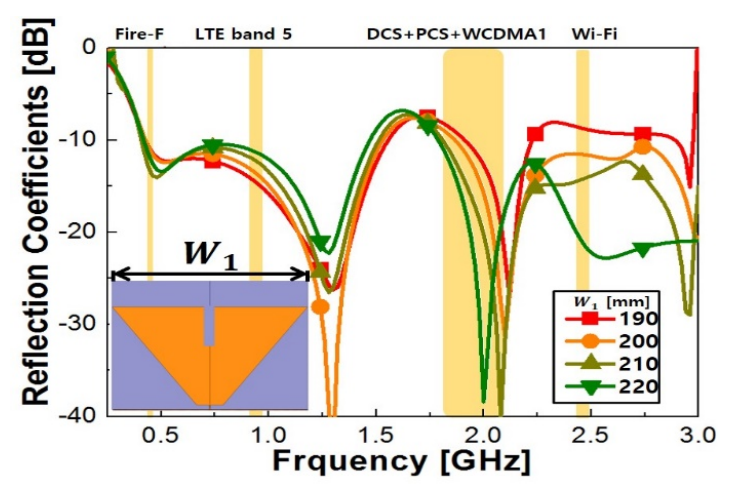

(g)
Fig. 2.

Fig. 2(a) and (b) depict the simulated reflection coefficients resulting from the change in $\mathrm{H}_{2}$ and $\mathrm{W}_{5}$, respectively. $\mathrm{H}_{2}$ and

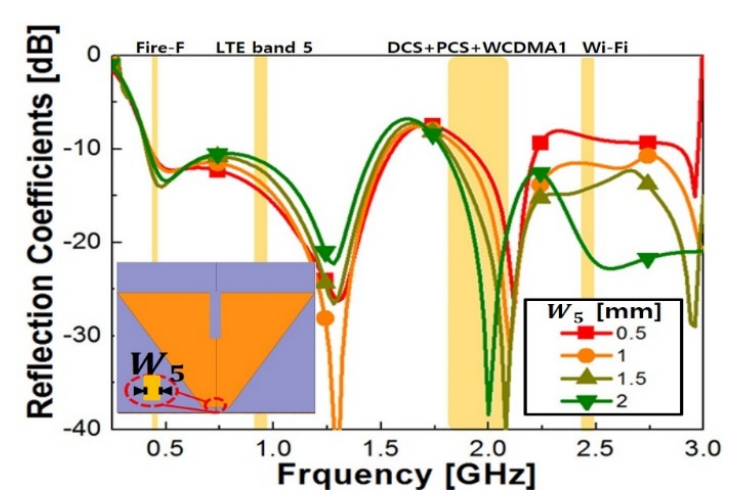

(b)

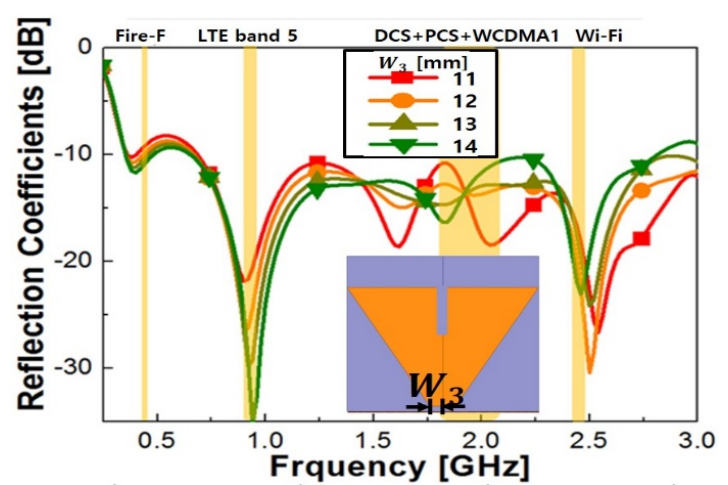

(d)

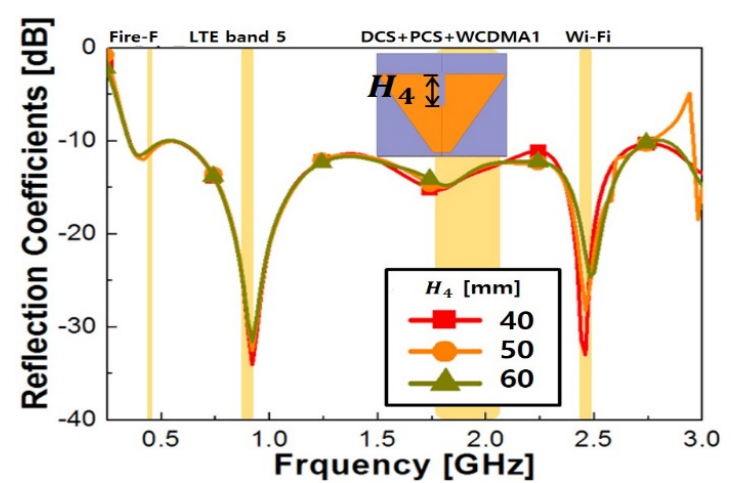

(f)

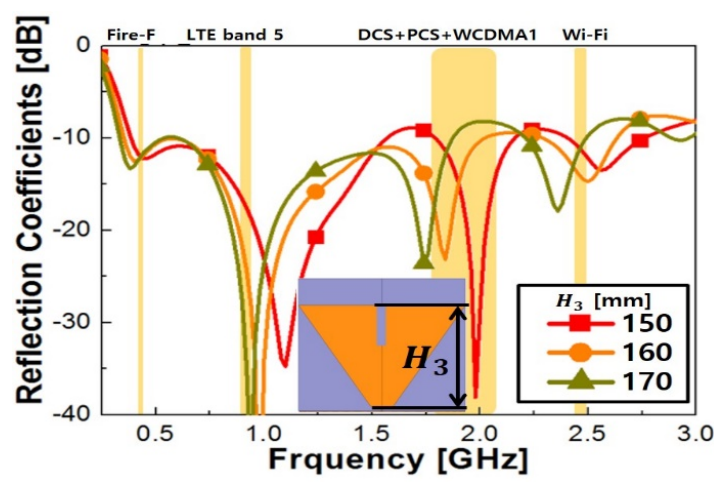

(h)

Fig. 2. Simulated reflection coefficients as functions of the variations in (a) $\mathrm{H}_{2}$, (b) $\mathrm{W}_{5}$, (c) $\mathrm{W}_{2}$, (d) $\mathrm{W}_{3}$, (e) $\mathrm{W}_{4}$, (f) $\mathrm{H}_{4}$, (g) $\mathrm{W}_{1}$, and (h) $\mathrm{H}_{3}$. 
$\mathrm{W}_{5}$ are the length and width of the transmission line, respectively, between the notch and the ground plane, indicated as the cross connection in Fig. 1(c). When the $\mathrm{H}_{2}$ length is altered in the simulation, the reflection coefficients in all bands are also changed. Variations in the $\mathrm{H}_{2}$ length are particularly influential on the firefighting radio band, and variations in the $\mathrm{W}_{5}$ width are less influential on the low-frequency bands than on the high-frequency Wi-Fi band. If the $\mathrm{H}_{2}$ length exceeds $6 \mathrm{~mm}$, the reflection coefficients suffer; thus, the $\mathrm{H}_{2}$ length is set to 6 $\mathrm{mm}$, and for similar reasons, the $\mathrm{W}_{5}$ width is set to $1 \mathrm{~mm}$. As shown in Fig. 1(b), the optimal reflection coefficients for parameters such as $\mathrm{H}_{1}, \mathrm{H}_{3}, \mathrm{H}_{4}, \mathrm{~W}_{2}, \mathrm{~W}_{3}, \mathrm{~W}_{4}$, and $\mathrm{W}_{5}$ are decided in a similar fashion.

Fig. 2(c), (d), (e), and (b) show the simulated reflection coefficients resulting from the change in $\mathrm{W}_{2}, \mathrm{~W}_{3}, \mathrm{~W}_{4}$, and $\mathrm{H}_{4}$, respectively. Although the discone and notch parameters with a reverse triangular structure are changed, the simulated reflection coefficients remain $-10 \mathrm{~dB}$ below in the interested band. Th is means that these parameters are not sensitive and have enough margin.

Fig. 2(g) and (h) illustrate the simulated reflection coefficients resulting from the change in the length and height of the notch, respectively. When the $\mathrm{W}_{1}$ length and the $\mathrm{H}_{3}$ height are altered in the simulation, the reflection coefficients in the highfrequency band of $2 \mathrm{GHz}$ above are slightly changed and almost maintained $-10 \mathrm{~dB}$ below in all bands simultaneously. As $\mathrm{W}_{1}$ and $\mathrm{H}_{3}$ are designed by considering an electric length operated in the low-frequency band, the variations in $\mathrm{W}_{1}$ and $\mathrm{H}_{3}$ are much less influential in the low-frequency band than in the high-frequency band. If $\mathrm{W}_{1}$ and $\mathrm{H}_{3}$ exceed $200 \mathrm{~mm}$ and 160 $\mathrm{mm}$, respectively, the reflection coefficients suffer; thus, $\mathrm{W}_{1}$ and $\mathrm{H}_{3}$ are set to $200 \mathrm{~mm}$ and $160 \mathrm{~mm}$, respectively.

\section{MEASUREMENT AND TeST Results}

Fig. 3 shows a photograph of the actual fabricated antenna. This antenna is a cross-shaped printed four-notch structure with an FR-4 epoxy substrate and a circular ground plane of $200 \mathrm{~mm} \phi$ diameter. As mentioned previously, the operating principle of a fabricated antenna with a reverse triangular structure fed by a probe through the center of the circular plate is based on a discone antenna structure. To satisfy the broad and multi-resonance bandwidth, an inverse discone structure is combined with a cross-shaped notch structure to realize the omni-directional pattern.

The measured results of the reflection coefficients of the fabricated antenna were analyzed using the HP Vector Network Analyzer 8722ES (Hewlett-Packard, Palo Alto, CA, USA). The radiation patterns and gains were measured in a $20 \mathrm{~m} \times 7$ $\mathrm{m} \times 7 \mathrm{~m}$ anechoic chamber. Thus, the results obtained were compared with simulated values to demonstrate the validity of the design.

Fig. 4 presents the comparison graph of the simulated and measured reflection coefficients of the proposed antenna that shows the simulation results to be generally generally consistent with the measured values. The broad and multi-bandwidth characteristics were observed by the measured reflection coefficients much lower than $-10 \mathrm{~dB}$. It is not so serious for data difference even though the measured data observed a little different from the simulated ones. Because the simulated reflection coefficients also shown $-10 \mathrm{~dB}$ below in the interested band.

Fig. 5 compares the simulated and measured two-dimensional (2D) radiation patterns on the $\mathrm{X}-\mathrm{Z}$ plane, with the measured patterns agreeing well with the predictions. Fig. 5(a) shows the omni-directional pattern at $445 \mathrm{MHz}$, which indicates that the ground size of $200 \mathrm{~mm} \phi$ is too small to compare with the operating frequency of $445 \mathrm{MHz}$. By contrast, measurements at $1,800,2,100$, and $2,450 \mathrm{MHz}$ show diminutive directional patterns toward $10^{\circ}$ to $50^{\circ}$ and $-10^{\circ}$ to $-50^{\circ}$. The measured patterns, as shown in Fig. 5, agree well with the predictions.

Fig. 6 shows the comparison of the simulated and measured $2 \mathrm{D}$ radiation $\mathrm{E}$-patterns on the $\mathrm{Y}-\mathrm{Z}$ plane. It is theoretically a matter-of-fact result that the simulated and measured radiation patterns are similar to the findings in Fig. 5 because of the crossshaped symmetrical structure. The measured patterns show rea-

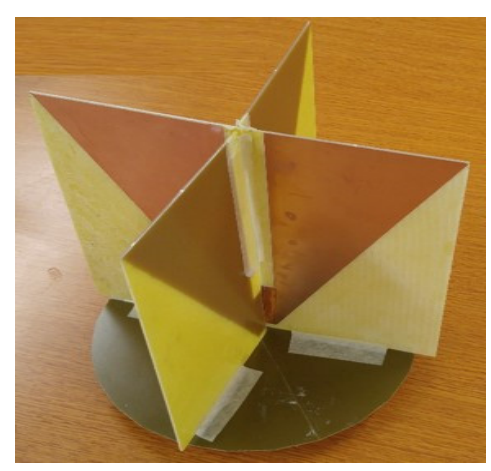

Fig. 3. Photograph of the fabricated antenna.

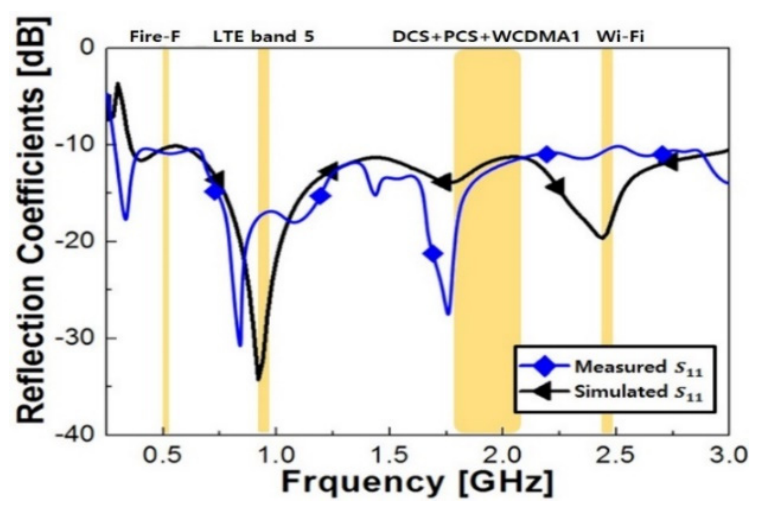

Fig. 4. Comparison of the simulated and measured reflection coefficients of the proposed antenna. 


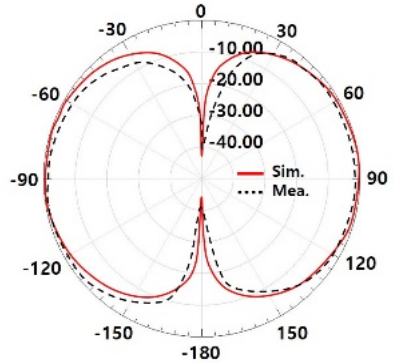

(a)

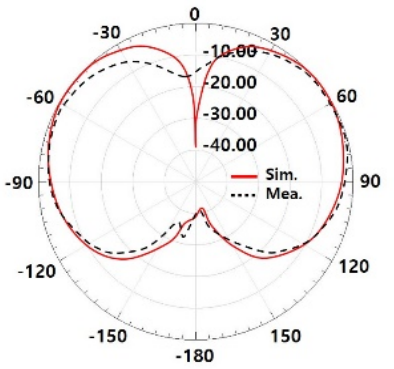

(b)

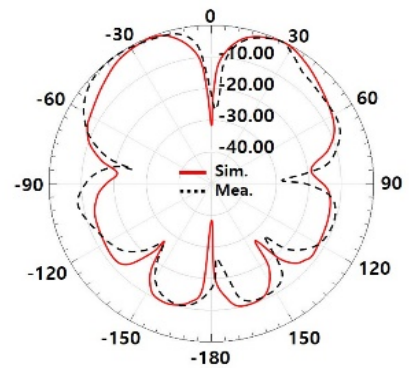

(c)

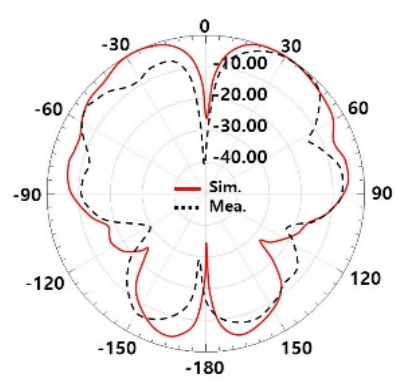

(d)

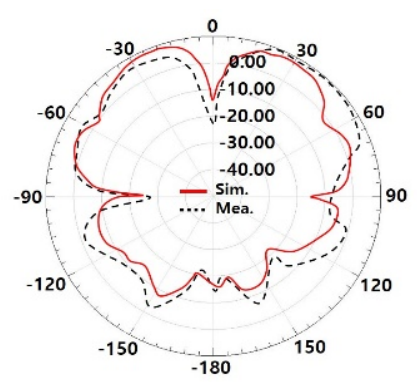

(e)

Fig. 5. Comparison of the simulated and measured 2D radiation patterns on the $\mathrm{X}-\mathrm{Z}$ plane: (a) $445 \mathrm{MHz}$, (b) $890 \mathrm{MHz}$, (c) $1,800 \mathrm{MHz}$, (d) 2,100 MHz, and (e) 2,450 MHz.

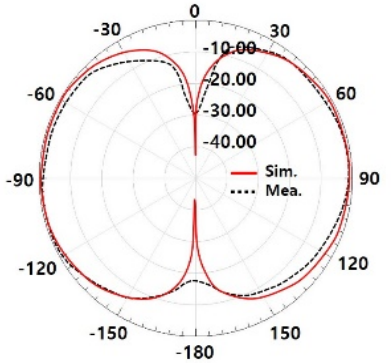

(a)

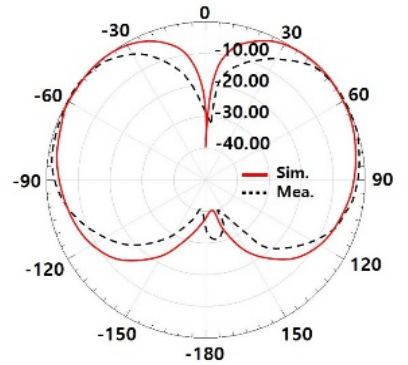

(b)

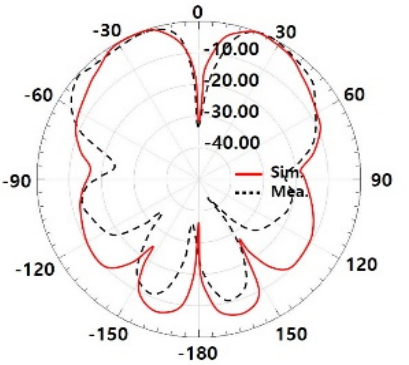

(c)

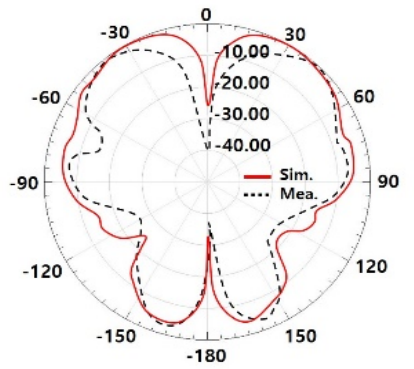

(d)

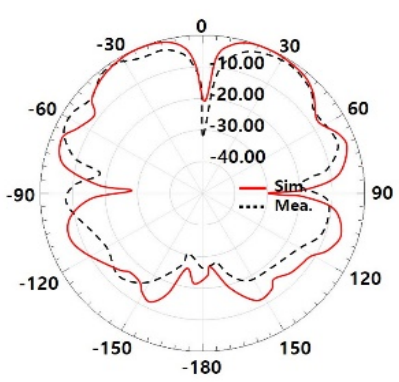

(e)

Fig. 6. Comparison of the simulated and measured 2D radiation patterns on the Y-Z plane: (a) $445 \mathrm{MHz}$, (b) $890 \mathrm{MHz}$, (c) $1,800 \mathrm{MHz}$, (d) 2,100 MHz, and (e) 2,450 MHz.

sonable agreement with the simulation.

Fig. 7 compares the simulated and measured 2D radiation patterns on the $\mathrm{X}-\mathrm{Y}$ plane, with the measured patterns agreeing well with the predictions. A distorted radiation pattern at 2.45 $\mathrm{GHz}$ is observed through the multiplication phenomenon of inherence frequency.
Fig. 8 shows the simulated and measured average gains of the proposed antenna. These gains are calculated by the root mean square for the radiation pattern at each frequency. As the proposed antenna size is relatively small in comparison with the wavelength of $400 \mathrm{MHz}$, the gain values observed at lowfrequency bands are low. Nevertheless, the measured gains show 


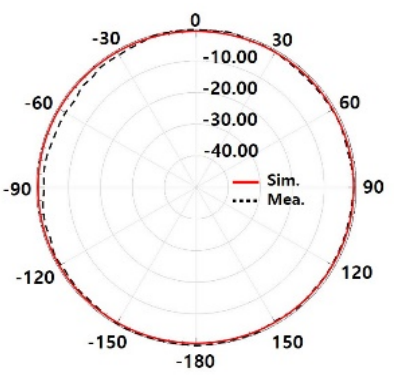

(a)

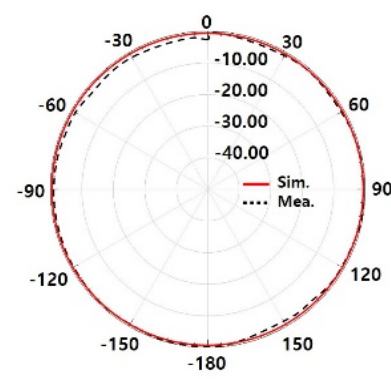

(b)

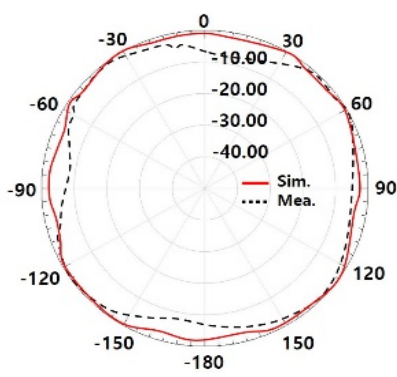

(c)

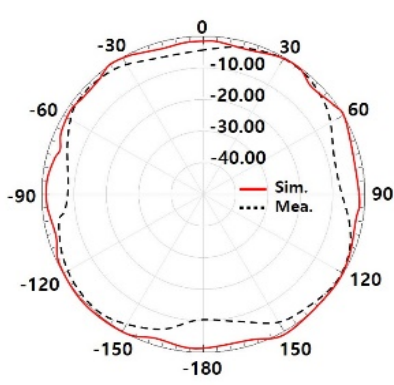

(d)

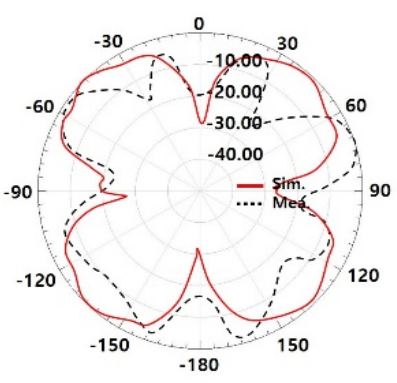

(e)

Fig. 7. Comparison of the simulated and measured 2D radiation E-patterns on the X-Y plane: (a) $445 \mathrm{MHz}$, (b) $890 \mathrm{MHz}$, (c) 1,800 MHz, (d) 2,100 MHz, and (e) 2,450 MHz.

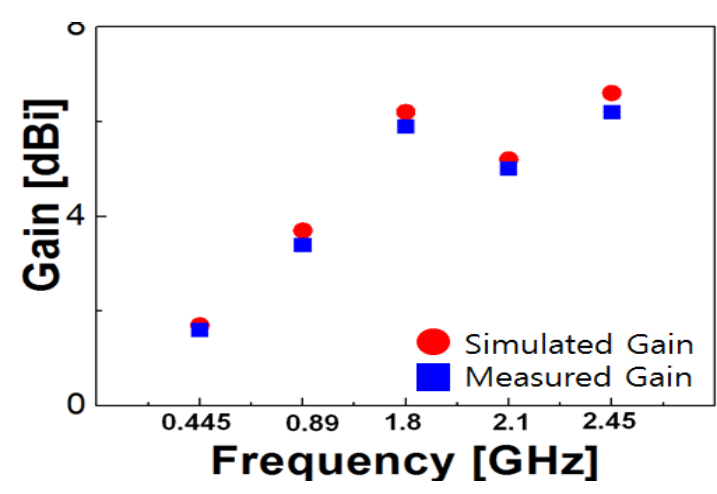

Fig. 8. Simulated and measured gains of the proposed antenna.

good agreement with the simulation.

\section{CONCLUSION}

A multiband cross-shaped inverse triangular notch antenna on circular ground plane for radio shadow zone mobile communication is proposed in this paper. The main feature of the proposed antenna is the broad and multi-bandwidth repeating antenna for in-building mobile communication services, including the firefighting radio band. Broad- and multi-bandwidth were achieved by finely adjusting the transmission line with the crossshaped notch antenna between the inverse triangular structure and the circular ground plane, optimizing the length and width of the notch through iterative simulation. The measured reflection coefficients were observed $-10 \mathrm{~dB}$ lower in the firefighting band (440-450 MHz) and the mobile repeater band (890$2,450 \mathrm{MHz}$ ), and they agreed well with those obtained through simulation. The desired omni-directional patterns by a crossshaped inverse triangular structure were obtained in the firefighting band, even though the radiation patterns in the $\mathrm{Wi}-\mathrm{Fi}$ band had directivity at $10^{\circ}$ to $15^{\circ}$ and $-10^{\circ}$ to $-50^{\circ}$. The measured radiating patterns and gains exhibited a reasonable degree of agreement with the predictions. Future works will focus on reducing the antenna size.

Following are results of a study on the "Leaders in Industry-university Cooperation +" Project, supported by the Ministry of Education and National Research Foundation of Korea.

\section{REFERENCES}

[1] S. Wang, S. Yoo, J. Park, H. Shim, and H. Choo, "Design of a broadband coupled-fed printed dipole antenna as an array element for direction finding systems," Journal of Electromagnetic Engineering and Science, vol. 19, no. 4, pp. 266271, 2019.

[2] K. E. Kedze, H. Wang, and I. Park, "Effects of split position on the performance of a compact broadband printed dipole antenna with split-ring resonators," Journal of Electromagnetic Engineering and Science, vol. 19, no. 2, pp. 115121, 2019.

[3] Y. Lee, J. Ha, and J. Choi, "Design of a wideband indoor repeater antenna with high isolation for $3 \mathrm{G}$ systems," IEEE Antennas and Wireless Propagation Letters, vol. 9, pp. 697- 
700, 2010.

[4] S. M. Kim, K. S. Min, and S. Y. Gang, "Design for multiband relay antenna with parasitic monopoles," in Proceedings of 2015 IEEE International Conference on Computational Electromagnetics (ICCEM), Hong Kong, China, 2015, pp. 115-117.

[5] S. M. Kim and K. S. Min, "Design of multiband repeater antenna with fire-fighting band for in-building mobile communication," The Journal of Korean Institute of Electromagnetic Engineering and Science, vol. 27, no. 6, pp. 495-503, 2016.

[6] K. S. Min, K. G. Lee, and Y. Kim, "Design of broadband repeater antenna with firefighting band for in-building mobile communication," in Proceedings of 2018 International Symposium on Antennas and Propagation (ISAP), Busan, South Korea, 2018, pp. 1-2.

[7] S. J. Yoon and J. Choi, "A low-profile broadband array antenna for home repeater applications," Journal of Electromag

\section{Kyeong-Sik Min}

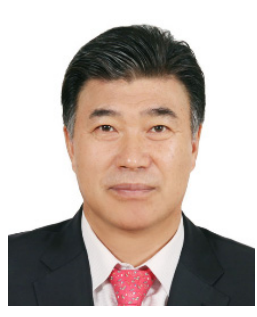

was born in South Korea. He received his B.E. and M.E. degrees in electronic communications engineering from Korea Maritime University, Korea, in 1989 and 1991, respectively. He received his Ph.D. degree in electric and electronics engineering from the Tokyo Institute of Technology, Japan, in 1996. Since 1997, he has been a professor at the Department of Radio Communication Engineering in Korea Maritime and Ocean University, Korea. From January 2017 to February 2018, he was a visiting professor at the California State University, Fresno, USA. His major research interest is the waveguide slot array antenna for military and mobile communication. Currently, his research is mainly focused on the high-gain slot array antenna for the coast monitoring of RADAR applications, the design of a multiband antenna for in-building mobile communication, the visual design antenna program development, and the radio regulation and policy in Korea. netic Engineering and Science, vol. 18, no. 4, pp. 261-266, 2018.

[8] X. Qing, Z. N. Chen, and M. Y. W. Chia, "UWB characteristics of disc cone antenna," in Proceedings of IEEE International Workshop on Antenna Technology: Small Antennas and Novel Metamaterials (IWAT), Singapore, 2005, pp. 97-100.

[9] A. Chen, T. Jiang, Z. Chen, D. Su, W. Wei, and Y. Zhang, "A wideband VHF/UHF discone-based antenna," IEEE $A n^{-}$ tennas and Wireless Propagation Letters, vol. 10, pp. 450-453, 2011.

[10] Y. Jin, J. Tak, and J. Choi, "Quadruple band-notched trapezoid UWB antenna with reduced gains in notch bands," Journal of Electromagnetic Engineering and Science, vol. 16, no. 1, pp. 35-43, 2016.

[11] Y. Liu, Z. Chen, and S. Gong, "Triple band-notched aperture UWB antenna using hollow-cross-loop resonator," Electronics Letters, vol. 50, no. 10, pp. 728-730, 2014. 